\title{
Sacheri por Campanella: del secreto a la pregunta de sus ojos
}

\section{Sacheri by Campanella: from the secret to the question in their eyes}

\author{
Alfredo Dillon alfredodillon@yahoo.com \\ http://orcid.org/0000-0001-7571-6693 \\ Instituto de Investigaciones; Facultad de Ciencias Sociales; \\ Universidad Católica Argentina (Argentina)
}

\section{Resumen}

La pregunta de sus ojos, la primera novela de Eduardo Sacheri publicada en 2005, fue el hipotexto en que Juan José Campanella basó su película El secreto de sus ojos (2009), una de las más taquilleras en la historia del cine argentino. El artículo se propone analizar los procedimientos de transposición, poniendo foco en los personajes, el punto de vista, la construcción de la temporalidad y el desenlace. También se comparan las relaciones que cada texto establece con la historia argentina y los temas que cada versión acentúa. A partir de la descripción de las diferencias entre ambos textos, se proponen claves de lectura para asignar sentido a las transformaciones de la novela a la película.

Palabras clave: Adaptación; transposición; literatura argentina; cine argentino; Juan José Campanella. 


\section{Abstract}

The Question in Their Eyes (La pregunta de sus ojos), the first novel by Argentine writer Eduardo Sacheri, published in 2005, was the hypotext for Juan José Campanella's The Secret in Their Eyes (2009), one of the most successful filmes in the history of Argentine cinema. This article aims to analyze adaptation procedures involving characters, point of view, construction of temporality and narrative ending. The relation of each text with Argentine history and the topics emphasized in each version are also compared. Description of differences between both texts is the basis for an accurate interpretation of the transformations that led from the novel to the filme.

Keywords: Adaptation; transposition; Argentine literature; Argentine cinema; Juan José Campanella.

En un célebre ensayo sobre Kafka, Borges propone un modo de leer según el cual cada escritor crea sus precursores: los itinerarios de lectura se modifican con cada obra; un texto nuevo no solo es capaz de influir sobre textos futuros, sino que puede también modificar la manera como leemos otros textos que lo precedieron. Algo así sucedió con El secreto de sus ojos (2009) de Juan José Campanella, una de las películas más exitosas del cine argentino reciente, con 2,4 millones de espectadores (INCAA, 2009). Basada en la novela La pregunta de sus ojos de Eduardo Sacheri (publicada originalmente por Galerna en 2005), en este caso la película -hipertexto, según la clasificación de Genette (1989)-, funcionó como precursora del texto literario -hipotexto-, aunque este haya sido editado primero.

El secreto de sus ojos fue la película más vista de 2009 en la Argentina y la más taquillera de la década 2001-2010, ganadora del Premio Oscar a Mejor Película Extranjera en 2010. El éxito del filmee de Campanella permitió redescubrir una novela que había pasado más bien desapercibida en el momento de su publicación, y la convirtió en un best seller, con nueve reimpresiones en la Argentina entre 2009 (cuando fue reeditada por Alfaguara, en coincidencia con el estreno de la película) y 2014. Incluso dio lugar a que se rebautizara la obra: en España (país que coprodujo la película), Alfaguara editó la novela bajo el título El secreto de sus ojos e ilustró la portada del libro con una foto de los actores Ricardo Darín y Soledad Villamil.

El guión de la película, escrito por Campanella y el propio Sacheri, también dio lugar a la canonización de este último dentro del campo cultural argentino. Luego del estreno del filmee, 
la novela -la primera de Sacheri, quien hasta entonces sólo había escrito cuentos- se tradujo a casi treinta idiomas (Diana, 2013). Su segunda novela, Aráoz y la verdad, fue llevada al teatro en 2010 por Gabriela Izcovich. Y en 2015 se estrenó la película Papeles en el viento (dirigida por Juan Taratuto), basada en su tercera novela.

Hortiguera sintetiza la trastienda del proceso de adaptación que dio lugar a la película:

Para 2007 ambos -autor y director- redactaron el guion y al año siguiente se inició el rodaje en la ciudad de Buenos Aires. Mientras tanto, la editorial Aguilar-Altea-Taurus-Alfaguara compraba los derechos del libro original editado por Galerna y, con unas pocas correcciones y modificaciones, lo reeditaba, muy oportunamente, unos meses antes del estreno de la película, con una faja que anunciaba: "La historia que inspiró la película de Juan José Campanella" (2010).

El vínculo entre director y escritor trasciende El secreto: Campanella ha mencionado la influencia del cuento "Esperándolo a Tito" en la concepción de Luna de Avellaneda (2004), que cuenta la historia de un club de barrio. Además, Sacheri es coguionista de Metegol (2013), otra historia centrada en el fútbol, tal vez el tema más emblemático de su obra. En ese sentido, la crítica suele colocar a Sacheri entre los autores de literatura futbolera, junto con Fontanarrosa, Osvaldo Soriano o Juan Sasturain.

Paradójicamente, en este caso el fútbol tiene mayor presencia en la película que en la novela: una de las secuencias más emblemáticas transcurre en el estadio de Racing, y la pasión por el fútbol será el elemento que permita descubrir al asesino. La huella del novelista en el texto se hace evidente también a partir de otros dos elementos: los acontecimientos narrados tienen un trasfondo histórico fundamental (y Sacheri es profesor de Historia); buena parte del relato transcurre en Tribunales (Sacheri explica, en una Nota del autor al final de la novela, que él mismo trabajó en un juzgado a fines de los ochenta, y que esa experiencia contribuyó a la "verosimilitud" [317] de la trama) (1).

\section{Los personajes y la construcción del punto de vista}

Uno de los principios constructivos de la narración, tanto en la novela como en el filme, es la identificación narrativa con el punto de vista del protagonista, Benjamín. Con respecto al protagonista surge una primera diferencia entre los textos: su apellido en la película es 
Espósito, mientras que en la novela era Chaparro; el narrador incluso menciona el contrasentido de que alguien con ese apellido midiera "un metro ochenta y cinco" (139).

El texto literario presenta a este personaje a partir de unos pocos rasgos ("Sesenta años. Alto. Canoso. La nariz aguileña, el rostro flaco" [9-10]), reproducidos con fidelidad en la película por la caracterización de Ricardo Darín, el actor fetiche de Campanella (y del cine argentino en general). Benjamín es un ex oficial de Justicia devenido escritor luego de su jubilación, cuando siente resurgir la incógnita de un caso que no había logrado resolver: el del asesinato de Liliana Colotto, la esposa de Ricardo Morales, a manos de Isidoro Gómez.

En la novela y en la película, la narración comienza cuando Benjamín, quien acaba de jubilarse luego de cuarenta años de trabajo en Tribunales, encara la escritura de un libro sobre el caso Colotto. Para eso, su primer paso es tomar prestada una máquina de escribir de la mujer de quien está enamorado, la jueza Irene Hornos (en la película, su apellido es Menéndez Hastings, lo que subraya su pertenencia de clase, uno de los rasgos que la volverían presuntamente inalcanzable para Benjamín). Irene será la primera y principal lectora de ese libro: el proceso de escritura es también un proceso de seducción. En la película, la máquina de escribir funciona como un motivo recurrente: denota el acto de escribir-recordar sobre el que se sostiene la trama policial, y a la vez connota el avance de la trama amorosa (su contraparte son los ojos de Inés).

En función de la economía narrativa que exige el largometraje, algunos detalles de la prehistoria de los personajes aparecen omitidos. Por ejemplo, en el filmee no hay referencias a los dos matrimonios previos de Benjamín (apenas se alude a uno); tampoco se narra, por ejemplo, el momento en que se conocen Morales y Liliana. Además, se omite un detalle que agrava la tragedia: en la novela, Liliana estaba embarazada en el momento en que fue asesinada.

Por otra parte, la película otorga mayor relieve al personaje de Pablo Sandoval (interpretado por Guillermo Francella) y, sobre todo, al de Irene (Soledad Villamil). El propio Sacheri reconoció en una entrevista que sus personajes "se complejizaron con la mirada de Campanella" (Repar, 2009).

A tono con la trayectoria de Francella, el personaje de Sandoval constituye el pilar del registro cómico en el filme. En ambos textos se lo caracteriza como un amigo leal y con problemas con el alcohol. Su muerte es eje de diferencias sustanciales: en la película es asesinado por fuerzas parapoliciales en una de las escenas de mayor impacto, mientras que en la novela su muerte es posterior, por enfermedad, y pasa más desapercibida. 
Irene, a su vez, adquiere una ternura y una cercanía que no llegan a recortarse en la novela, dado que su presencia allí resulta siempre mediada por la conciencia del narrador: en el texto literario ella es apenas un nombre, el objeto del discurso amoroso de Benjamín, mientras que en la película adquiere la inmediatez de la presencia corporal y participa de algunas de las acciones centrales de la trama, como el interrogatorio a Gómez. El texto literario incluso hace explícita la intención de omitir precisiones con respecto a este personaje: el narrador protagonista sostiene que se ha propuesto "no decir una palabra en estas páginas" (221) sobre la mujer que ama.

El texto original de Sacheri mantiene la focalización en Benjamín (con excepción de unos pocos capítulos), pero alterna entre dos narradores: uno en tercera persona, con predominio de estilo indirecto libre, encargado de los capítulos que llevan título ("Despedida", "Cine", "Teléfono", etcétera); otro en primera persona, intradiegético, que corresponde al propio Benjamín, "autor" de un libro dentro del libro, cuyos capítulos no tienen título pero sí aparecen numerados. El narrador-personaje incluso defiende la elección de la primera persona ("Me queda más cómoda" [21]) y se presenta a sí mismo como una mezcla de "testigo" y "protagonista" de los hechos que va a narrar, según el mismo, "sin inventar nada" (21) (2).

A la vez, el narrador en tercera persona describe las escenas de escritura y hasta retoma lo escrito por el narrador-personaje: "Chaparro tira de la hoja que acaba de terminar con la suficiente energía como para liberarla del rodillo sin romperla y la relee. Las últimas palabras lo hacen sonreír" (136). Este narrador comenta los episodios relatados en el libro dentro del libro, y problematiza el objeto de ese texto: se pregunta si Benjamín está escribiendo la historia de Ricardo Morales, la de Isidoro Gómez, o la suya propia ("una suerte de autobiografía" [277]).

Hacia la mitad de la novela -cuando Morales se entera de que el asesino Gómez ha quedado detenido-, el narrador llega a proponer que el relato termine ahí, reclamando un happy end ("Ha contado el crimen, la pesquisa y el hallazgo. El malo está preso y el bueno está vengado. ¿Por qué no concluir con este final feliz y ya?” [187]). Ese falso desenlace también es sugerido por la narración cinematográfica, que introduce en ese momento el primer fundido a negro, dividiendo en dos partes la historia, señalando un posible final y marcando, a la vez, la inevitabilidad de un nuevo giro.

La película tampoco está exenta de reflexiones meta narrativas, que emergen principalmente del personaje de Inés y su lectura de la novela que escribe Benjamín. Como señala Acosta Larroca (2009), la principal crítica del personaje recoge un cuestionamiento habitual al cine de Campanella: el tratamiento melodramático de las historias de amor. 
La instancia de narración aparece representada dentro de la novela: el relato es, en rigor, la escritura del recuerdo del protagonista. La figura del narrador-personaje implica, entre otras cuestiones, un mayor acceso del receptor a la subjetividad y la conciencia del protagonista. En el filme, en cambio, no hay un narrador-personaje que asuma la enunciación por medio de la voz en off, salvo por una breve secuencia al comienzo, que muestra a Benjamín escribiendo y leyendo la historia de Morales.

La puesta en escena del acto de escritura permite retomar, de manera casi literal, las palabras del hipotexto. Así, por ejemplo, en una de las secuencias que muestran a Benjamín escribiendo, el espectador llega a leer las últimas líneas de la página, que coinciden casi literalmente con las que el narrador-personaje utiliza en la novela para describir la reacción de Morales al enterarse de la muerte de Liliana: "[Como si, una vez asentada] la humareda del polvo de su vida hecha pedazos, Morales pudiera empezar a avizorar su propio futuro. $Y$ comprobar que, sin lugar para el equívoco, su futuro era nada" (49).

Incluso algunas secuencias de diálogo retoman literalmente las palabras de la novela, como cuando el personaje xenófobo de Pedro Romano acusa a dos albañiles de haber asesinado a Colotto, y luego de mencionar que uno de ellos es paraguayo, aclara sobre el otro: "Este por lo menos es argentino". Algunas líneas de la escena clave del interrogatorio al asesino Gómez (interpretado por el actor español Javier Godino) también se repiten en la novela y la película. La confesión de Gómez se produce luego de una provocación por parte de los investigadores ("Este pibe no pudo haber sido"; "Hay que ser muy hombre para enganchar a una mujer asi'): en la novela, esa función corresponde a Benjamín y Sandoval, mientras que en la película Sandoval es reemplazado por Irene.

En El secreto, el espectador solo es testigo de aquello que Benjamín vive, recuerda o imagina. Esta condición de espectador-testigo se construye también por medio de los encuadres, siempre cercanos a los actores. Muchas veces la cámara parece escondida entre los objetos de la escenografía, como si el espectador estuviera espiando a los personajes. Dicha posición se sostendrá hasta la última secuencia, cuando Irene cierre la puerta y el espectador quede del otro lado, abandonando a la pareja protagónica justo en el comienzo de su romance.

En la novela, algunos capítulos correspondientes al narrador-Benjamín quiebran el punto de vista que rige en casi toda la novela, abandonando la focalización del Benajmín-personaje. Es el caso del capítulo 13, que transcurre en Tucumán y tiene como protagonista al padre de Liliana Colotto, un personaje omitido en la película: en esta, su función -descubrir que Isidoro Gómez está en Buenos Aires- se ha desplazado al personaje de Morales. Tampoco respetan el punto de vista de Benjamín como testigo el capítulo 19 (que narra la captura de Gómez, 
efectuada por un guarda de tren) y los capítulos 24 y 25 (en los que la focalización se traslada al personaje de Gómez, preso en la cárcel de Devoto, y se narra el encuentro entre Gómez y Romano, quien lo recluta para la "contraguerrilla").

De todos modos, es la conciencia de Benjamín la que rige la narración en ambos textos. De ahí la mención recurrente de los ojos de Irene, objetos privilegiados de la atención -y el amor- del protagonista, que funcionan como un leitmotiv desde el comienzo hasta el final. Esas menciones se traducen en primerísimos planos en la película, y justifican la persistencia de los ojos en el título, mientras que la pregunta de la novela (referida a la interrogación amorosa que supone para Benjamín la mirada de Irene) será reemplazada en la película por el secreto (un enigma referido, más bien, a la mirada -también enamorada- de Isidoro Gómez en las fotos). Por otra parte, como bien señala Malpartida (2011: 361), en la película hay una dosis mayor de secreto porque la narración comienza sin que el protagonista conozca el verdadero desenlace de Gómez y Morales; en la novela, en cambio, Benjamín inicia la escritura de su libro con la trama policial ya cerrada: para él, a la vez narrador y protagonista, no hay secreto.

En el filme, representar el pasado supone apelar a la memoria y la imaginación. La cámara recurre al fuera de foco, que "borronea" algunas escenas de la misma manera que el recuerdo elimina infinidad de detalles para quedarse solo con aquello que importa. La imaginación rellena los huecos de la memoria; el protagonista imagina aquello que no sabe cómo sucedió. El espectador, obligado a seguir en todo momento la focalización de Espósito, resulta incapaz de distinguir en algunos tramos de la narración cuánto de lo que ve "ocurrió" de esa manera, y cuánto ha sido imaginado por el protagonista (no se sabe, por ejemplo, si la muerte de Sandoval es consecuencia de un sacrificio heroico o de un simple error de los asesinos). La memoria se evidencia entonces como un trabajo de evocación, pero también de invención. El tratamiento fotográfico parece basarse en la idea de que la memoria simplifica, omite detalles y adquiere su vivacidad a partir del ejercicio de recordar, anclado siempre en el presente.

\section{Tiempo narrativo y tiempo histórico}

En los dos textos (literario y audiovisual), la narración se configura por medio de la alternancia entre dos líneas temporales, presente y pasado, que en la novela corresponden a narradores diferentes. Sin embargo, una de las principales diferencias entre la novela y la película tiene que ver precisamente con la organización temporal del relato. En El secreto la acción oscila entre fines de los años noventa (el presente de la narración) y 1974-1975, los años previos al 
golpe de Estado de 1976, cuando la represión paraestatal ya operaba por medio de la Triple A durante el gobierno de María Estela Martínez de Perón. El relato oscila constantemente entre estos dos tiempos, y son las escenas del pasado las que tienen los colores más saturados, mientras que en el presente la pantalla tiende a volverse más gris. De esta manera, la imagen elude el cliché cinematográfico que asocia los tonos sepia a las secuencias que transcurren en el pasado.

Campanella ubica su thriller político en el contexto del gobierno democrático de 1974-1975, justo antes del último golpe militar. Algunas escenas fundamentales de la película transcurren en el Ministerio de Bienestar Social, emblema de una estructura que encubría a la Triple A durante el tercer período peronista. En esta película el Estado es un refugio para los peores criminales, un ámbito donde ascienden los asesinos y los corruptos. Esto queda claro en la escena -montada digitalmente- que muestra en televisión al asesino Isidoro Gómez como custodio de la Presidenta en 1975. En la secuencia siguiente, cuando la pareja protagónica se acerca al Ministerio, descubren que allí ha ascendido Romano, el ex compañero de Benjamín, caracterizado por la deshonestidad y la xenofobia. La escena en la que Irene y Benjamín son amenazados por Isidoro Gómez en el ascensor -en descenso, como el país- sintetiza el nuevo funcionamiento del Estado, basado en la violencia y la impunidad.

La concentración de la acción en 1974 y 1975 responde a una decisión del director. La versión original del relato ubicaba los hechos en diferentes momentos históricos:

-Benjamín e Irene se conocen en Tribunales en 1967;

-el asesinato de la joven Liliana Colotto se produce en 1968, durante la dictadura de Juan Carlos Onganía;

-Isidoro Gómez es capturado en 1972, durante el gobierno de facto de Alejandro Agustín Lanusse;

-el asesino es liberado con la amnistía para presos políticos decretada por Héctor Cámpora en mayo de 1973 (3); Morales se entera por el diario y decide mudarse a Villegas, como primer paso de su plan de venganza;

-el intento de asesinato de Benjamín por un grupo paramilitar ocurre durante la dictadura de Videla, en 1976, y motiva la huida del protagonista a Jujuy (ese viaje inaugura la película, con la emblemática escena de la despedida en la estación de tren);

-Sandoval muere, luego de una larga enfermedad, en 1982, y Benjamín visita Buenos Aires con el trasfondo de la Guerra de Malvinas; 
-finalmente, el relato salta a 1996, en pleno gobierno de Carlos Menem, cuando Benajmín recibe la carta de Morales que le permitirá cerrar el caso.

En la novela, el pasado de la narración (1968-1996) es abordado en el libro dentro del libro escrito por Espósito, mientras que el presente (ubicado en el año 1999) corresponde a los capítulos presentados en tercera persona.

En varias entrevistas Campanella explicó que la condensación temporal de la historia en apenas dos años obedeció a una "urgencia dramatúrgica", pero también a cuestiones presupuestarias vinculadas con el costo de la reconstrucción histórica, que incluyó el montaje digital de elementos emblemáticos del período elegido, como las imágenes de archivo de la ex presidenta Isabel Perón. Así justifica Campanella la elección del período 1974-1975:

\footnotetext{
Elegimos una época que no estaba tocada por el cine, y sigue sin estarlo: la época del peronismo antes de la dictadura. De la dictadura se hizo mucho en el cine, a tal punto que hablás con los jóvenes que nacieron en democracia y piensan que los militares fueron extraterrestres que bajaron de un ovni, un 24 de marzo, en una sociedad que era feliz y democrática. Lo importante es ver cómo la cosa se desvía, de a poco, hasta que la vas naturalizando (Abadi, 2016).
}

Efectivamente, este contexto "democrático" previo al golpe de Estado ha sido mucho menos transitado por el cine argentino que la dictadura iniciada en 1976. Las alusiones a "la subversión", "la Argentina que se viene" y los agentes paraestatales capaces de "hacer lo que hay que hacer" son elementos que contribuyen a desdibujar las fronteras entre democracia y dictadura, y exhiben de manera incómoda los gérmenes del Terror que ya estaban latentes en el período constitucional previo al golpe.

La narración da cuenta de una democracia que trastabilla, en la que el Estado no solo ha dejado de ser el garante de los derechos de sus ciudadanos, sino que ha comenzado a eliminarlos, en un proceso que la dictadura profundizará y llevará a niveles inéditos en la historia argentina. La película de Campanella viene a plantear que la categoría dictadura no alcanza para comprender la violencia paraestatal. Por otra parte, la interpretación del pasado reciente que propone el filme cuestiona, al menos indirectamente, la memoria sostenida por el discurso kirchnerista, del que es contemporáneo:

Si la "teoría de los dos demonios" se edificaba en torno de la imagen de una sociedad inocente, víctima pura de una violencia que no guardaba ningún lazo con ella, la interpretación que el 
gobierno [kirchnerista] transmite estiliza la militancia de los años setenta y borra por medio de esa estilización no sólo a los partidos armados de la época, sino la guerra intestina del peronismo, la Triple A, en fin, todo aquello que fue degradando la vida pública nacional antes del Golpe de Estado (Altamirano, 2007: 17).

En este sentido, probablemente la principal diferencia que aporta la película en relación con el tratamiento del pasado reciente en el cine nacional sea la elección del contexto democrático que precedió a la dictadura como marco para la acción narrativa. Al ubicarse en los años previos al golpe de Estado, Campanella presenta una democracia ya permeada por la represión ilegal y la violencia paraestatal. A partir de su alusión a fechas y personajes reconocibles para el espectador, el director parece apostar a que su película funcione como herramienta de conocimiento histórico. La "lección" de Campanella apuntaría a evidenciar cómo los gérmenes de la violencia dictatorial ya estaban presentes en los años previos al golpe, cuestionando de esa manera la idea de que el 24 de marzo de 1976 implicó una ruptura total en la historia argentina y el inicio de un período radicalmente nuevo, sin conexiones con el proceso histórico anterior.

La novela de Sacheri, en cambio, omite toda referencia directa a Isabel Perón, López Rega y la Triple A, pero profundiza en la descripción de la represión desatada por la dictadura militar que comenzó en 1976. Es en ese momento que Benjamín ve amenazada su vida (un grupo de tareas destroza su departamento y lo amenaza de muerte) y huye a Jujuy. El texto incluye referencias a la desaparición de personas ("Todos los días veíamos detener gente por ahí" [231]); y menciona los secuestros, la tortura y la ignorancia (o indiferencia) de buena parte de la sociedad, entre ellos el propio Benjamín.

Ambos textos despliegan una mirada pesimista sobre la situación política del país. El Estado se presenta como una ineficaz máquina burocrática, sintetizada en el filme en las columnas de papeles que se acumulan sobre los escritorios de los personajes que trabajan en Tribunales. El Poder Judicial aparece como un nido de corrupción, donde los jueces no se interesan por hacer justicia y los funcionarios son capaces de atrapar perejiles (habitualmente, pobres o inmigrantes) con tal de dar por cerrada una causa. En la novela, el protagonista cuestiona a "Onganía y su ballet" (141); advierte que en 1972 en el país "empezaban a sobrar cadáveres" (163); señala en 1973 que la realidad se ha vuelto un "desbarajuste general" (207); y lamenta, a lo largo de la narración, la "siniestra impunidad" (143) frente a los constantes abusos y delitos cometidos por la Justicia y los militares.

Por otra parte, la construcción del espacio narrativo apela a la familiaridad de ciertos lugares reconocibles para el espectador argentino. En la novela, esa familiaridad se busca por medio 
de la mención de calles concretas (Talcahuano, Tucumán, Niceto Vega, etcétera), de referencias al colectivo 115 o a la estación de Once. En el cine, nombrar exige mostrar. el espectador reconoce de inmediato las escaleras del Palacio de Tribunales, la estación de Retiro o la cancha de Huracán. Estas locaciones, presentadas en amplios planos generales, otorgan espesor a la presencia de la ciudad de Buenos Aires, aportan color local y, como efecto de los encuadres, subrayan la pequeñez y la impotencia de los personajes ante las fuerzas que deben enfrentar.

\section{Memoria, melancolía y pasión}

La historia no solo apela a la memoria (colectiva) del pasado reciente como contexto de la acción dramática, sino que además tematiza la memoria (individual) por medio de las reflexiones de dos de los personajes principales (Benjamín Chaparro/Espósito y Ricardo Morales), presentados como sujetos aferrados a un recuerdo irresuelto del pasado. El texto de Sacheri destaca la importancia de este tema desde la dedicatoria: "A mi abuelita Nelly. Por enseñarme lo valioso que es conservar y compartir la memoria" (7).

La novela presenta al viudo Morales como un personaje memorioso: lo primero que menciona el narrador-Benjamín es su capacidad para recordar minuciosamente los detalles relacionados con su mujer muerta, y destaca su "fidelidad en el recuerdo" (24). Para Morales, recordar a Liliana es una manera de mantenerse fiel a ella. $Y$ casi 30 años después del crimen, cuando el protagonista recibe una carta de Morales, se encuentra con que este sigue poseído por la memoria: “¿No pasaba el tiempo, para este hombre? ¿Todo era un eterno presente que se sumaba a los anteriores?" (288).

En El secreto, los personajes plantean que el pasado puede construirse: se eligen los recuerdos -aun cuando no se pueda renunciar a ellos-, y se eligen las versiones de aquello que se desconoce. Morales lo explicita hacia el final de la película, cuando intenta convencer a Espósito de la necesidad de olvidar: "Elija bien. Lo único que nos queda son recuerdos. Al menos, que sean lindos. [...] No le dé más vueltas. [...] Va a tener mil pasados y ningún futuro". Junto con la memoria y la melancolía, el filme introduce otro tema recurrente en el cine de Campanella: las pasiones. Los protagonistas de Campanella son, en cierta medida, Quijotes que persiguen utopías moderadas: comenzar un nuevo restaurant en El hijo de la novia, sostener el funcionamiento del club de barrio en Luna de Avellaneda, defender un pequeño pueblo del avance de una corporación en Metegol, hacer justicia en medio de la desidia y la 
corrupción estatal en El secreto de sus ojos. En esta última, el personaje de Guillermo Francella hace una defensa encendida de las pasiones (un hombre "no puede cambiar de pasión", le explica a Benjamín), y sostiene que son esas pasiones las que definen la "esencia" de un hombre, aquello a lo que no puede renunciar: su identidad. La trayectoria de los Bildungsromane de Campanella va desde una vida gris y mediocre hacia una vida plena de pasión: en sus películas, los protagonistas aprenden a transformar sus vidas huecas llenándolas de sentido, es decir, viviendo sus pasiones.

La pasión adquiere también en la película la forma de un amor idealizado: el protagonista se deslumbra con la devoción que Morales siente por su esposa muerta, e incluso llega a envidiarlo por eso. Aquella pasión, indestructible frente al paso de los años, hace que Benjamín se identifique con Morales: eso mismo siente él por Irene. "¿Se imagina lo que debe ser un amor así, sin el desgaste de lo cotidiano, de lo obligatorio?", pregunta el protagonista. En la novela, Benjamín hace explícita su identificación con el otro personaje: "Fue en ese momento cuando tomé conciencia, creo, de que Morales me recordaba mucho, o demasiado, a mí mismo" (67).

A la vez, Benjamín se ha identificado con Gómez, un hombre frustrado por un amor no correspondido: gracias a esa identificación logra descubrir en las fotos el secreto que escondía la mirada de Gómez. En la novela, el protagonista confiesa: "Si yo reparé en esa forma de mirar era porque también había escudriñado a otra mujer del mismo modo" (126). En la película, esto se ve confirmado en una foto -también pretérita- en la que Benjamín aparece, como Gómez, mirando de reojo a la mujer que ama.

El texto literario construye dos amores idílicos que funcionan en espejo: por un lado, el vínculo entre Morales y Liliana, exento de todo conflicto ("Sentía que tener a Liliana era una felicidad abusiva, que nada tenía que ver con lo que había sido el resto de su vida" [25]); por el otro, el amor (silenciado) entre Benjamín e Irene ("Chaparro sabía que nunca había dejado de amarla, y que una mezcla de azar, sentido común y cobardía la habían mantenido siempre ajena" [8384]). La idea del amor platónico funciona como contraste de las relaciones que han construido Benjamín e Irene hasta el presente de la narración: aunque ambos se casaron, ninguno fue plenamente feliz, porque su "verdadero amor" era otro y, en la lógica de estas narraciones, el verdadero amor permanece inmutable, como una verdad esencial.

\section{El final: venganza y castigo privado}


Las películas de Campanella suelen dividir a la crítica, pero ninguna lo hizo tanto como El secreto de sus ojos. La principal polémica ha girado en torno al final de la historia. Por un lado, la trama amorosa se resuelve con un happy end: el protagonista se decide a vivir su historia de amor con Irene, de manera más explícita en la película que en la novela, que termina justo antes de que Benjamín entre al despacho de la jueza a confesarle sus sentimientos ("Chaparro necesita responderle a esa mujer, de una vez y para siempre, la pregunta de sus ojos" [315]). La película resulta más explícita, al retomar en la última escena varios leitmotivs sembrados a lo largo de su desarrollo (como la puerta cerrada en el despacho de la jueza, o el pasaje del "temo" al "te amo" cuando el protagonista rellena los huecos dejados por la máquina de escribir).

Por otro lado, en la película la trama policial (y política) queda abierta. En la anteúltima escena, Espósito decide no intervenir cuando descubre que, 25 años después del crimen que da comienzo a la película, el viudo Ricardo Morales tiene prisionero en su casa al asesino. En otras palabras, Espósito hace silencio frente a la venganza de Morales: desencantado por su propia experiencia con la justicia de los tribunales, convalida por omisión la justicia por mano propia. Aunque la película termina en ese momento -y no explicita, por lo tanto, qué hará Espósito con lo que acaba de descubrir-, el silencio del protagonista frente a la escena de la cárcel doméstica bien puede interpretarse como una aceptación tácita.

Es un final sorpresivo pero, a la vez, anticipado: desde el comienzo, Morales ha insistido en la necesidad de un "castigo" y en su rechazo a la pena de muerte ("Le darían una inyección y se quedaría dormido lo más pancho. No es justo"). Ante el descrédito del Estado y las instituciones públicas, el desenlace de la película reivindica la validez de la justicia por mano propia. El relato parece advertir que, cuando el Estado no responde a las demandas de sus ciudadanos, deja el terreno libre para que se impongan soluciones individuales.

El triunfo de la reparación privada para un problema público ha motivado comparaciones con la otra película argentina ganadora del Oscar, La historia oficial (1985), que también aborda los años setenta. La lectura de González (2010) contrapone ambos filmes al señalar que el de Luis Puenzo traza una trayectoria desde lo privado hacia lo colectivo, en tanto que la película de Campanella propondría un repliegue sobre la esfera privada:

Mientras que en La historia oficial, que era más ingenua y pedagógica, actuaba el movimiento social y la discusión en el seno de una familia de apropiadores tenía un desenlace inscripto en la corriente reconstructora del pensamiento colectivo, en El secreto de sus ojos, veinticinco años después, hay resarcimiento de un particular que se convierte en victimario, sacando los hechos de la espera reparatoria común. 
En la novela, Morales sostiene metódicamente su venganza durante más de veinte años. Pero el texto de Sacheri carece de la apertura incómoda del filme: por un lado, porque el protagonista "cierra" el caso tres años antes del presente de la narración (escribe en 1999, y su viaje a la casa de Morales en Villegas fue en 1996). Por otro lado, porque la decisión del protagonista no involucra complicidad con el castigo privado: a diferencia de la película, no hay un reencuentro entre Benjamín y Morales, sino que estos retoman contacto por medio de una carta enviada por el viudo. Cuando Benjamín llega a la casa de campo, Morales se ha suicidado y ha asesinado a Gómez: el protagonista queda eximido de la connivencia con este castigo. De todos modos, en la novela el narrador-protagonista -cuyo punto de vista domina el relato- también toma posición a favor de la justicia por mano propia (incluso avala, antes de conocer el destino de estos personajes, la posibilidad de que Morales haya asesinado a Gómez: "Creo que yo habría hecho lo mismo" [261], confiesa).

El protagonista entierra el cuerpo de Gómez y esconde las pruebas de la cárcel clandestina: la policía solo conocerá el suicidio del viudo. La víctima, en este caso, no es la justicia sino la verdad. Paradójicamente, el olvido llega al final del ejercicio (catártico) de memoria que ha significado para el protagonista la escritura de su novela. Solo a partir de ese olvido el protagonista logra dar vuelta la página y avanzar con su mayor cuenta pendiente: la concreción de la historia de amor con Irene. "Llamativamente, desde que ha contado todo, [Morales y Gómez] ya no lo asaltan, no lo perturban, no lo increpan a cada rato" (313): olvidados estos personajes -y sus respectivos delitos-, la trama policial concluye y da lugar al cierre de la trama amorosa.

En cambio, el silencio cómplice de Espósito en El secreto interpela de modo más inquietante a los espectadores, ya que la narración se ha identificado con su perspectiva -en términos perceptivos, pero también morales- desde el comienzo. De esta manera, el final obliga al público a ser cómplice de la decisión del protagonista y aceptar una salida individualista -una venganza- como modo de "reparación" del crimen cometido.

\section{Comentarios finales}

Algunas de las escenas de mayor impacto de El secreto de sus ojos son creaciones de la versión cinematográfica, como la despedida de Benjamín e Irene en la estación de tren, el asesinato de Pablo Sandoval, la escena -muda- en que Gómez amenaza a Irene y Benjamín en un ascensor, o la más emblemática: la captura de Isidoro Gómez en el estadio de fútbol (en 
un plano secuencia de cinco minutos, que comienza con una toma aérea de toda la cancha y continúa, sin cortes, con una cámara en mano que acompaña a los personajes en la persecución). Cada una de estas escenas condensan densidad narrativa e impacto visual, además de apelar a ciertos elementos cristalizados en el lenguaje cinematográfico (la estación de tren como espacio de separación de los amantes, la persecución como secuencia prototípica del policial, el espejo como recurso para reponer el fuera de campo). Mientras la novela se despliega a lo largo de un arco temporal más amplio, la película concentra: la duración histórica de los hechos se reduce, así como se omiten acciones de los personajes para dar lugar a un relato con menos situaciones, pero más cargadas de significado.

A diferencia de otras transposiciones, en este caso el hipertexto ha funcionado casi como texto primero, arrojando luz posteriormente sobre un hipotexto que había logrado menor impacto, y cuya circulación fue más bien una consecuencia del texto segundo: La pregunta... se convirtió en "la novela que inspiró El secreto de sus ojos". ¿Cómo interpretar ese éxito de taquilla, que luego repercutió en la generación de un best seller?

Aunque en la última década se estrenaron muchísimas películas argentinas sobre los años setenta, ninguna fue tan exitosa en términos de público. En este éxito incidieron distintos factores: El secreto es una película industrial (entendiendo industrial como una categoría económica y no estética), encabezada por actores populares (Ricardo Darín, Guillermo Francella, Soledad Villamil, Pablo Rago) y construida según los códigos del género policial y el melodrama romántico. También tiene el respaldo de la firma de un director consolidado en el campo cinematográfico: Campanella ya había logrado gran éxito con sus películas anteriores y venía de ser candidato al Oscar con El hijo de la novia en 2002.

La película, además, tiene una impronta menos local que la novela, escrita en un tono deliberadamente porteño y colmada de referencias al contexto inmediato (desde el diario Crónica hasta los nombres de calles y barrios). En el filme, no exento de referencias concretas a Buenos Aires, los localismos aparecen depurados y tamizados por un lenguaje cinematográfico deudor del cine hollywoodense.

En términos narrativos, también contribuyó a la masividad de la película el hecho de que, aunque se refería a un período violento de la Historia argentina, lo hacía con una mínima carga de violencia explícita. Probablemente otro ingrediente crucial haya sido el fuerte esquematismo moral -relativizado recién al final, con la última decisión del protagonista-: no hay ambigüedad en los personajes buenos ni en los malos, las diferencias entre unos y otros están claramente delineadas. En este sentido, el filme de Campanella sacrifica una posible caracterización 
realista a manos de un planteo maniqueo, propio de los códigos del melodrama y del policial clásico antes que del policial negro.

Finalmente, aunque aquí se trata de un crimen pasional y no uno político, no puede desatenderse que la película elige el castigo privado aun cuando fue filmeada en una época los años 2000- en que las condiciones políticas abrían la posibilidad de garantizar un juicio público para personajes como Gómez (quien, según la construcción ficcional de la película, participó en la represión paraestatal bajo el ala del Ministerio de Bienestar Social, a cargo de López Rega). Al final, el protagonista decide olvidar lo que ha visto y seguir adelante con su vida por medio de la relación amorosa con Irene: ese olvido supone el fracaso del Estado y la derrota de la justicia en manos de la venganza.

\section{Notas}

(1) Las citas textuales de la novela corresponden a la siguiente edición: Sacheri, Eduardo (2014). La pregunta de sus ojos (1 ${ }^{\mathrm{a}}$ ed., 9 ${ }^{\underline{a}}$ reimp.).Buenos Aires: Alfaguara.

(2) Sacheri explica en una entrevista que las reflexiones metaliterarias del narrador surgen de sus propias disyuntivas como escritor: "Para la novela necesité ponerle a Chaparro mis propias dudas: tiempos verbales, personas, cómo narrar lo que no vio, dónde terminar la historia, hasta dónde contarla" (Friera, 2009).

(3) Según explica Sacheri en la Nota del autor que cierra el libro, fue una historia surgida de esa amnistía lo que dio lugar a la novela: "Una mañana cualquiera mis compañeros más experimentados me contaron una vieja anécdota: a raíz de la amnistía para presos políticos que el gobierno de Cámpora dictó en 1973, y en circunstancias que quedaron en la más completa oscuridad, salió en libertad un preso común que estaba detenido en la cárcel de Devoto" (316).

\section{Bibliografía}

Abadi, J. E. (2016). Entrevista a Juan José Campanella. Viva, 10 de enero. Recuperado de https://clar.in/21x5mNP

Acosta Larroca, P. (2009). El secreto de sus ojos: el mismo autor, la misma obra. Grupo Kane. Revista de Cine y Artes Audiovisuales, septiembre de 2009. Recuperado de https://bit.ly/2HbOr3T

Altamirano, C. (2007). Pasado presente. En Lida, C.; Crespo, H. y Yankelevich, P. (comp.). Argentina, 1976. Estudios en torno al golpe de estado (pp. 17-33). México: El Colegio de México.

Barthes, R. (2006). La cámara lúcida: nota sobre la fotografía. Buenos Aires: Paidós. 
Diana, E. (2013). Eduardo Sacheri: Fútbol, cine y pasión. Rumbos, 10 de diciembre. Recuperado de https://bit.ly/2luvx7V

Friera, S. (2009). Escribir es decir siempre algo que tenés atravesado. Entrevista a Eduardo Sacheri por La pregunta de sus ojos. Página/12, 3 de agosto. Recuperado de www.pagina12.com.ar/diario/suplementos/espectaculos/4-14788-2009-08-03.html

Genette, G. (1989). Palimpsestos. La literatura en segundo grado. Madrid: Taurus.

González, H. (2010). Las dificultades de la historia. Página/12, 7 de marzo. Recuperado de www.pagina12.com.ar/diario/suplementos/radar/9-5980-2010-03-07.html

Hortiguera, H. (2010). Políticas del recuerdo y memorias de la política en El secreto de sus ojos de Juan José Campanella. Ciberletras. Journal of literary criticism and culture, 24, pp. 1-13. Recuperado de www.lehman.cuny.edu/ciberletras/v24/hortiguera.html

Instituto Nacional de Cine y Artes Audiovisuales (INCAA) (2009). Anuario 2009 de la industria del cine. Recuperado de http://fiscalizacion.incaa.gov.ar/index_publicaciones.php

Malpartida, R. (2011). El secreto de sus ojos o cómo vivir una vida vacía: de la literatura al cine. Revista de Crítica Literaria Latinoamericana, 73, Lima-Boston, pp. 353-376.

Repar, M. (2009). Eduardo Sacheri: 'Mis personajes se complejizaron con la mirada de Campanella', $\tilde{N}$. Revista de Cultura, 18 de agosto. Recuperado de http://edant.revistaenie.clarin.com/notas/2009/08/18/_-01980156.htm 